\title{
Cultura e educação na sociedade
} contemporânea

\author{
Ana Regina Carrara \\ Maria do Carmo Brant de Carvalho \\ Thais Lima
}

Vivemos numa sociedade marcada por avanços tecnológicos que possibilitaram uma nova dinâmica nos fluxos de informação e na velocidade de sua produção, mas concomitantemente marcada por desigualdades sociais e econômicas que, juntamente com outros fatores, têm resultado na criação de uma forma específica de desigualdade: aquela que hierarquiza diferentes culturas e/ou limita o acesso aos bens culturais existentes. Esse último aspecto chama em particular nossa atenção. Dados do Ministério da Cultura demonstram que o acesso da população aos bens culturais é muito baixo, revelando um desconhecimento em relação à produção artística existente no Brasil, mesmo num contexto em que a proliferação da informação é indiscutível. Tendo em vista esses dados, este ensaio coloca em pauta a questão da educação e da cultura na sociedade da informação. Argumentamos que, ao se propiciarem situações de aprendizagem que levem em conta o patrimônio cultural, criam-se possibilidades de contato com formas diferenciadas de se relacionar com 0 mundo, favorecendo-se a valorização da diversidade cultural existente e ampliando-se o acesso às manifestações e práticas culturais, aprendizagens cuja construção sinaliza o enfrentamento das desigualdades de acesso à cultura, assim como de suas hierarquizações.

Palavras-chave: educação; cultura; diversidade cultural; desigualdades de acesso à cultura; democratização da cultura 


\title{
Culture and education in the
} contemporary society

\author{
Ana Regina Carrara \\ Maria do Carmo Brant de Carvalho \\ Thais Lima
}

We live in a society marked by technological advances that permitted new dynamics in information flows and in the speed of their production, but simultaneously marked by social and economic unbalances that, added to other factors, have resulted in the creation of a specific form of inequality: the one that hierarchizes different cultures and/or limits the access to the existing cultural goods. This last aspect particularly calls our attention. Data from the Ministry of Culture demonstrate that people's level of access to cultural goods is very low, disclosing an unawareness in relation to the artistic production existing in Brazil, even in a context in which the proliferation of information cannot be denied. In view of such data, this essay puts on the agenda the issue of education and culture in information society. We claim that, when one provides learning situations that take into consideration the cultural assets, possibilities are created for contact with distinct ways of relating with the world, benefitting from the valuation of the existing cultural diversity and expanding the access to the cultural manifestations and practices, learning the construction of which signals the fight to the inequality of access to culture, as well as its hierarchization.

key words: education; culture; cultural diversity; inequalities of access to culture; democratization of culture 


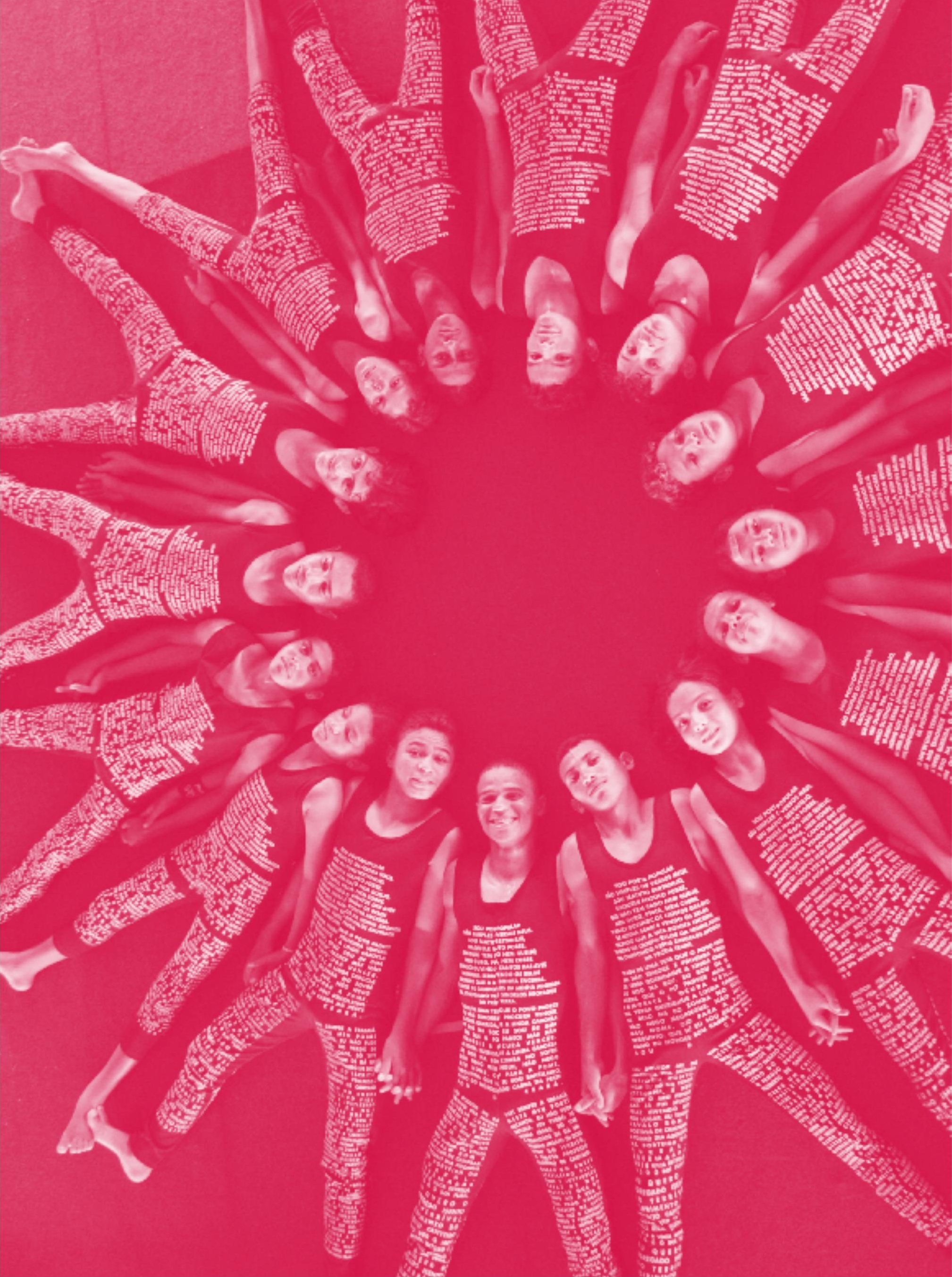




\section{Cultura e educação na sociedade contemporânea}

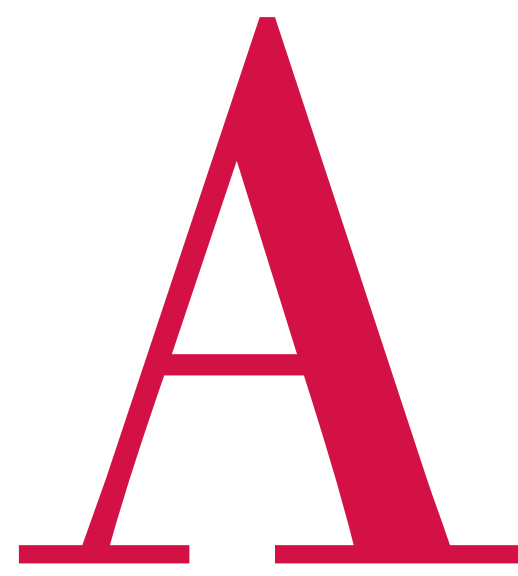

O ciclo histórico em que nos encontramos está inteiramente tomado pela mudança acelerada, ininterrupta e cumulativa. Nele, entrecruzamse inovações tecnológicas e modificações socioculturais que repercutem sobre todos os planos e setores da vida social.

Marco Aurélio Nogueira

s sociedades contemporâneas estão sendo configuradas e reconfiguradas pelo contínuo e acelerado avanço científico e tecnológico e, em particular, pelas chamadas tecnologias da informação e comunicação (TICs).

Esse avanço possibilitou uma nova dinâmica dos fluxos de informação e potencializou as interações e trocas entre pessoas de todo o planeta, ao mesmo tempo em que valorizou o conhecimento, como principal ativo dos indivíduos e das sociedades, e as redes sociais, compreendidas como o modo mais eficaz de atuação nas relações pessoais e no mundo do trabalho.

Nesse contexto, o tema da sustentabilidade permeia as agendas das diversas organizações societárias em face

* Ana Regina Carrara é historiadora e colaboradora do Cenpec desde 2004.

MARIA Do CARMo BRANT de CARVAlHo, assistente social, é doutora em Serviço Social e pós-doutorada em Ciência Política pela École des Hautes Études en Sciences Sociales de Paris e Superintendente do Cenpec.

THAIS LIMA, assistente social, é mestre em Serviço Social pela PUC-SP e especialista de carreiras da Training Innovations, Canadá. 
das contradições econômicas, sociais, ambientais, educacionais e culturais que afetam a humanidade.

Ao lado da imensa produção de conhecimento e de riquezas tangíveis e intangíveis, vive-se simultaneamente uma época marcada por enormes desigualdades sociais e econômicas, que são visíveis não apenas em uma análise comparativa internacional, mas no interior mesmo de diversos países como o Brasil.

Os conflitos políticos, econômicos, étnicos e religiosos se fazem conflitos culturais que produzem e reproduzem a diferença sectária, o isolamento social dos vários grupos marginalizados, a guetificação e a violência. Perde-se o grande motor da cultura: a valorização da potência do ser humano.

Valores, tradições e expressões culturais compartilhados são imprescindíveis para que os cidadãos se reconheçam pertencentes a uma história, território e grupo específico e constituam, portanto, as identidades das diferentes nações e etnias. Vale lembrar que não se pode confundir tradições culturais com fundamentalismo cultural, este acirrado pelas desigualdades que depreciam as culturas de outros, consideradas estranhas e inferiores ${ }^{2}$.

Mas há na cultura - enquanto expressões, saberes e valores - uma dimensão secular que se apresenta como resistência, mobilizando sem cessar a solidariedade na convivência, o respeito à diferença, a decantação do belo e do justo, e não deixa morrer a ética e a estética. 0 desafio da busca pela sustentabilidade, em todas as suas dimensões - política, econômica, social e ambiental tem forte respaldo nessa força da cultura.

É a partir desse paradigma que se faz necessário refletir sobre o contexto atual. A sociedade que nos toca viver é caracterizada pela sua complexidade: uma sociedade multifacetada, tecida pela velocidade de mudanças constantes e cumulativas, provocadas pelos avanços científicos e, sobretudo, pelo aumento das possibilidades de acesso às redes de informação e de consumo.

Vivemos numa sociedade movida pelo conhecimento e pela informação; numa sociedade-rede, com novos atores e movimentos sociais que incidem cada vez mais o seu papel protagônico na definição da agenda política dos Estados. As organizações não governamentais, com todas as suas contradições e mesmo particularismos, alargam e revitalizam a esfera pública.

\section{(...) a missão da educação} continua sendo formar pessoas capazes de construir sua vida e o mundo com ética e dignidade. É dessa compreensão que surgem os quatro pilares da educação promulgados pela Organização das Nações Unidas para a Educação, a Ciência e a Cultura UNESCO: aprender a conhecer, aprender a ser, aprender a fazer e aprender a conviver.

\section{A sociedade do conhecimento}

\section{A valorização do conhecimento e da informação nas} sociedades contemporâneas recarrega a importância da educação e da cultura como temas prioritários das políticas públicas.

A educação, em sentido abrangente, pertence à sociedade e se produz por um incansável movimento de realimentação sociopolítica, sendo impulsionada por um conjunto dinâmico e complexo de sujeitos e inter-relações: desde famílias, organizações do território, grupos sociais, organizações de ensino, movimentos sociais, coalizões, organizações multilaterais, institutos e fundações empresariais até órgãos governamentais de educação que a regulam e ofertam serviços educacionais.

A educação, pela via de suas agências, desempenha um papel importante por ser a responsável oficial pela transmissão dos saberes socialmente valorizados e considerados fundamentais às futuras gerações. Mas a sociedade de hoje, chamada sociedade do conhecimento, introduz novos modos instigantes de produzir conhecimento e, portanto, de aprender. Os fluxos e a distribui- 
ção da informação democratizaram-se de tal modo que podemos falar de uma sociedade não apenas de informações e conhecimentos compartilhados, mas de múltiplas possibilidades de aprendizados compartilhados. Somos todos aprendentes que circulam em uma roda de fluxos contínuos.

Assim, o papel das instituições de ensino já não pode se restringir à transmissão de conteúdos: é tarefa infrutífera e pouco eficaz. As novas gerações são interativas, dialógicas, e portam uma nova racionalidade cognitiva em que o aprender se faz descentrado e difuso. São gerações competentes para acessar e processar um conjunto simultâneo de informações, conhecimentos e experiências. $\mathrm{Na}$ condição de aprendentes, circulam por espaços concretos e reais e também por meios e circuitos virtuais como twitter, orkut, facebook, celulares e outros.

No entanto, a missão da educação continua sendo formar pessoas capazes de construir sua vida e o mundo com ética e dignidade. É dessa compreensão que surgem os quatro pilares da educação promulgados pela Organização das Nações Unidas para a Educação, a Ciência e a Cultura - UNESCO: aprender a conhecer, aprender a ser, aprender a fazer e aprender a conviver ${ }^{3}$.

Nessa perspectiva, a cultura não é apenas mediação privilegiada para a educação. Cultura e educação se vinculam irrevogavelmente. Acessar, fruir, processar e criar são uma mesma espiral cultural e educacional. Essa tessitura conjunta constrói conhecimentos e saberes, vivências e valores, objetividade e subjetividade.

\section{Patrimônio, arte e conhecimento.}

\section{A cultura expressa os diversos modos de existir dos}

diferentes grupos humanos, incluindo os modos de lidar com a natureza, as manifestações imateriais - os jeitos de cozinhar, dançar e tantos outros -, bem como os produtos materiais que resultam das produções concretas e das construções empreendidas pelo seres humanos ${ }^{4}$.

Dessa noção, deriva a compreensão de patrimônio cultural como o conjunto de elementos da cultura que é valorizado como bem a ser preservado e ensinado:

Patrimônio é tudo o que criamos, valorizamos e queremos preservar: são os monumentos e obras de arte, e também as festas, músicas e danças, os folguedos e as comidas, os saberes, fazeres e falares. Tudo enfim que produzimos com as mãos, as ideias e a fantasia 5 .
A seleção de personagens históricos, lugares, saberes e obras que são e serão futuramente considerados como patrimônio cultural - e, portanto, transmitidos às futuras gerações nos processos educativos - se dá por meio de disputas simbólicas que definem quais aspectos da cultura são ou não considerados como patrimônio.

Essa seleção se mostra inevitável por causa das limitações de tempo (duração) e recursos do ciclo educacional realizado pelas instituições de ensino e principalmente em razão das disputas por poder travadas entre os diferentes grupos sociais.

Os interesses políticos e econômicos conflitantes dos diferentes grupos que compõem as sociedades resultam em disputas pela hegemonia sobre a memória coletiva que compõe o patrimônio cultural. Na concepção do historiador francês Pierre Nora, a relação que temos com a memória é intermediada por determinados agentes e, portanto, não constitui uma relação espontânea, e sim mediada pelos chamados "lugares da memória” e pelos agentes ou agências que nos remetem a uma leitura/rememoração do passado.

Assim, as memórias se constituem como uma construção histórica que estabelece um discurso sobre o passado, de acordo com um projeto político que deseja consolidar aquele discurso.

Entendemos, assim, que o patrimônio cultural transmitido às futuras gerações por meio de processos educativos compõe-se por modos de ser e fazer e por valores de diferentes grupos sociais, cujos projetos políticos são distintos e divergentes entre si.

No cenário contemporâneo, em que o grande desafio é a formação de pessoas que articulem diferentes saberes, de modo que assumam posturas comprometidas social, ética e politicamente, um dos grandes desafios da educação passa a ser propiciar situações de aprendizagem que interconectem diferentes áreas do saber e coloquem as pessoas em contato com manifestações e produções culturais diversas.

A experiência de aproximar-se e conhecer outras formas de se relacionar com o mundo, de se relacionar consigo mesmo e com o outro e outras maneiras de expressar e criar ideias e sensações de modos antes desconhecidos favorece a valorização da diversidade cultural existente no mundo, no Brasil e em cada um de nós.

Nesse sentido, a arte ganha relevância ao possibilitar o encontro com o que existe de mais diverso, belo e transcendente no ser humano, pois: 
A arte tem o papel de tornar o mundo digno de ser vivido, reencantando-o, tornando-o um lugar não apenas de luta pela sobrevivência cotidiana, mas um lugar de imaginação criadora, de sonho e de utopia. É fundamental reafirmar a importância da arte como impulso transformador de pessoas portadoras de uma nova visão do ser humano, capaz de elevar sua autoestima, de humanizar e emancipar o espírito ${ }^{6}$.

Valendo-se das habilidades humanas fundamentais - audição, visão, tato, paladar e olfato - e de diferentes linguagens - cênicas, plásticas, musicais e do corpo -, a arte se constitui como uma força comunicadora central para se promover a aproximação das pessoas a saberes e experiências consideradas importantes nos processos educativos de diferentes grupos.

Nesse sentido, a arte propicia a construção de conhecimentos diversificados de forma interligada, reconectando saberes do campo da matemática, da geografia, da história, da física, das relações sociais, da engenharia, da psicologia e de tantas outras áreas do saber que estão presentes nas diferentes obras e produções artístico-culturais realizadas por pessoas e grupos pertencentes a culturas diversas.

\section{A potência dos encontros}

\section{Ao refletirmos sobre a importância dos processos}

educacionais e da cultura no cenário contemporâneo, assim como a potência da arte para propiciar conhecimentos diversificados, nos deparamos com alguns desafios que ainda dificultam a articulação dos saberes do campo da educação e da cultura.

0 acesso da população brasileira a grande parte das produções culturais - sejam elas peças teatrais, shows ou apresentações musicais, espetáculos ou mostras de dança, exibições de filmes, acesso a livros e outros bens culturais - é assustadoramente baixo:

- apenas $13 \%$ dos brasileiros frequentam cinema alguma vez por ano;

- $92 \%$ nunca frequentaram museus;

- $93,4 \%$ jamais foram a uma exposição de arte; e

- $78 \%$ dos brasileiros nunca assistiram a um espetáculo de dançar.

Os fatores que geram esse baixo acesso da maioria da população às produções culturais envolvem o preço dos ingressos e produtos - livros, CDs, DVDs e outros -

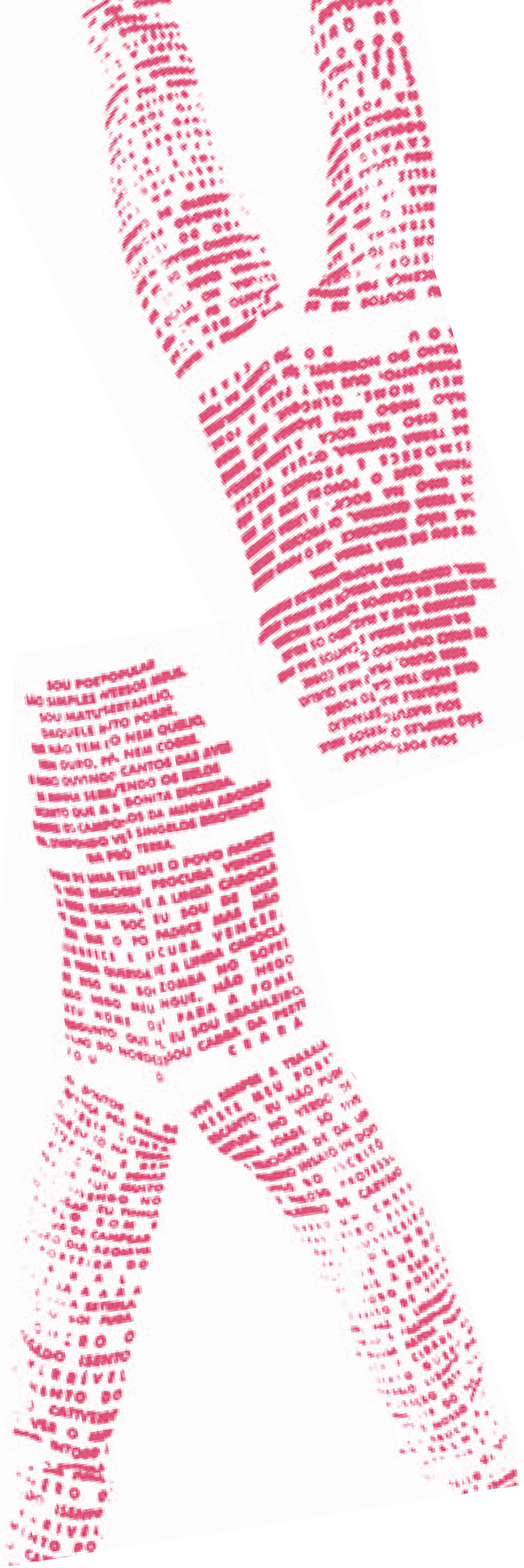


Colocar em contato

"aprendentes" de

diferentes regiões, idades, gêneros $e$ origens étnicas, estimulando

a troca de saberes $e$ experiências e propiciando

o reconhecimento e a valorização das diferenças e semelhancas culturais existentes, é uma tarefa fundamental para se promover conhecimentos significativos $e$ o fortalecimento de vínculos essenciais à cidadania.

e o desconhecimento da população sobre as produções artísticas existentes nas diferentes regiões e comunidades brasileiras.

Isso significa que, além do custo de algumas produções ser elevado, muitas pessoas nunca tiveram a oportunidade de assistir a uma peça teatral ou escutar outros tipos de música além daqueles que seu grupo social mais próximo - família e amigos, por exemplo - costuma ouvir.

Esse grande desafio é também uma grande oportunidade. Oportunidade para que nós, profissionais comprometidos com a formação de pessoas e envolvidos direta ou indiretamente com a educação, possamos ampliar o acesso à arte, às manifestações tradicionais, às produções experimentais e ao grande universo de produções artístico-culturais do Brasil e da humanidade.

Colocar em contato "aprendentes" de diferentes regiões, idades, gêneros e origens étnicas, estimulando a troca de saberes e experiências e propiciando o reconhecimento e a valorização das diferenças e semelhanças culturais existentes, é uma tarefa fundamental para se promover conhecimentos significativos e o fortalecimento de vínculos essenciais à cidadania.
Acessar, interagir e construir novos conhecimentos a partir da diversidade cultural expressa nas produções artístico-culturais e nas relações com pessoas pertencentes a outros contextos culturais é um caminho decisivo para a integração entre cultura e educação e, principalmente, para a promoção do desenvolvimento sustentável do ser humano no planeta.

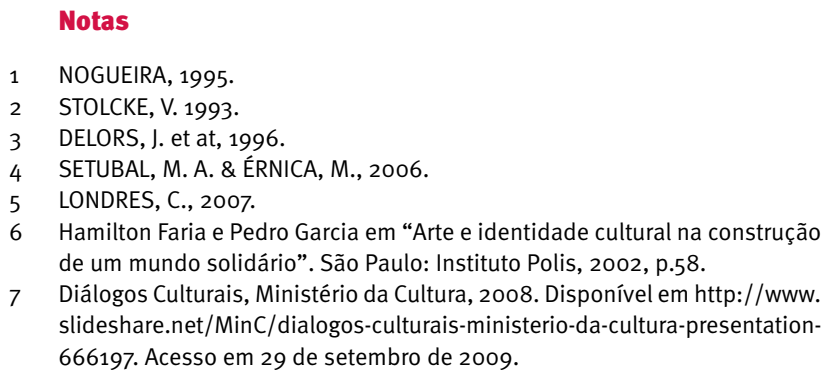

7 Diálogos Culturais, Ministério da Cultura, 2008. Disponível em http://www. slideshare.net/MinC/dialogos-culturais-ministerio-da-cultura-presentation666197. Acesso em 29 de setembro de 2009.

\section{Referências}

DELORS, Jacques et al. Educação: um tesouro a descobrir. Relatório para a UNESCO da Comissão Internacional sobre Educação para o Século XXI. 4.ed. São Paulo: Cortez; Brasília: UNESCO, 1996.

INAGAKI, Alexandre. Os tempos, eles estão sempre mudando: a proliferação dos espaços onde se escreve, se lê, se fala e se ouve cultura. Continuum. São Paulo, n.6, p.5-8, dez. 2007.

LONDRES, Cecília. In: Patrimônio cultural imaterial: para saber mais. Brasília: IPHAN/MinC, nov. 2007.

NOGUEIRA, M. A. Para uma governabilidade democrática progressiva. Lua Nova. São Paulo, Cedec, n.36, 1995.

NORA, Pierre. "Entre memória e história: a problemática dos lugares". In: Lês lieux de mémoire, I La Republique. Paris, Gallimard, 1984, pp.XVIII-XLII. Traduzido por Yara Aun Khoury.

PORTO, Marta. "Construindo o público a partir da cultura: gestão municipal e participação social”. Disponível em http://www.martaporto.com.br/dialogos/wp-content/uploads/2008/og/tex_construindo.pdf. Acesso em 29 de setembro de 2009.

SETUBAL, Maria Alice \& ÉRNICA, Maurício. “Por que educação e cultura?” Cadernos Cenpec/Centro de Estudos e Pesquisas em Educação, Cultura e Ação Comunitária: Educação e cidade. n.1. São Paulo: Cenpec, 2006.

STOLCKE, Verena. “Cultura Européia: uma nova retórica de exclusão?” Revista Brasileira de Ciências Sociais, n.22, ano 8, jun. 1993. 


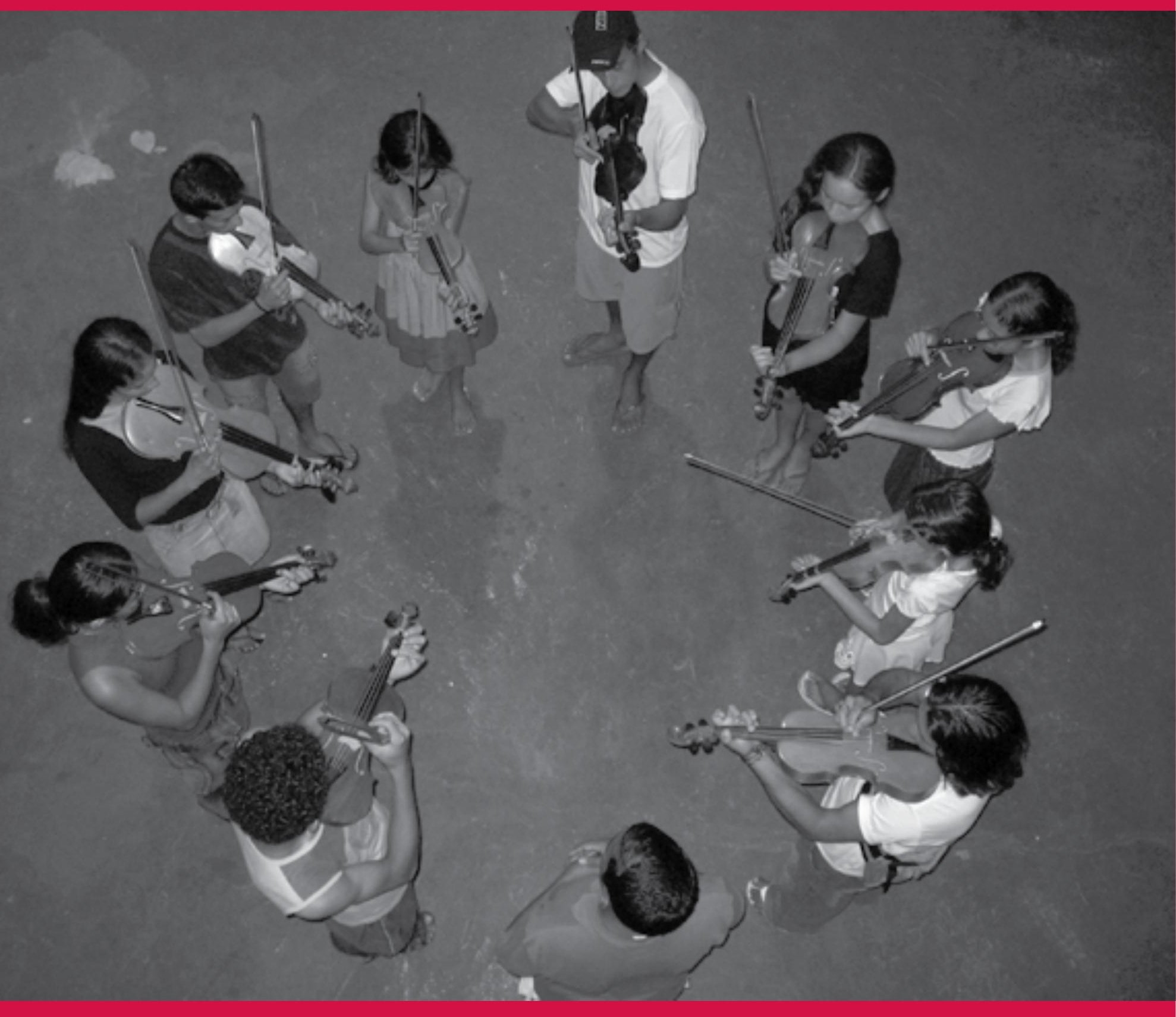

